See Article page XXX.

\section{Commentary: Aortic dissection and chronic oral anticoagulation: An IlLUMENating perspective?}

\author{
Abe DeAnda, Jr, MD, ${ }^{\mathrm{a}}$ and Sean G. Yates, $\mathrm{MD}^{\mathrm{b}}$
}

In chronic aortic dissection, conventional wisdom maintains that persistence of the false lumen (FL) is associated with disease progression and poorer long-term outcomes relative to FL thrombosis. ${ }^{1,2}$ Even partial thrombosis has been linked to aortic expansion. ${ }^{3}$ These observations are similar in patients with surgically repaired acute type A aortic dissection with persistent distal disease. Although the principal etiology of progressive aortic dilatation is FL patency, advancements in surgical techniques (eg, open distal anastomoses, frozen elephant trunks) have reduced the likelihood of long-term patency. Given the reported association between FL thrombosis and improved patient outcomes, intuitively, the use of anticoagulant medications to prevent the onset of thrombosis would lead to inferior outcomes relative to prohemostatic agents that enhance secondary hemostasis or medications without an impact on hemostasis. However, in this issue of the Journal, Vendramin and colleagues ${ }^{4}$ have suggested that perhaps chronic oral anticoagulation $[\mathrm{OAC}]$ is not a terrible idea. In their retrospective analysis of a single-institution experience, the authors found that chronic OAC resulted in greater persistent late FL patency rates without an associated increase in adverse outcomes. These study findings should provide some reassurance when considering chronic OAC in patients with comorbidities associated with an increased

\footnotetext{
From the a Division of Cardiovascular and Thoracic Surgery, Department of Surgery, UTMB-Galveston, Galveston; and ${ }^{\mathrm{b}}$ Division of Transfusion Medicine and Hemostasis, Department of Pathology, UT Southwestern, Dallas, Tex.

Disclosures: The authors reported no conflicts of interest.

The Journal policy requires editors and reviewers to disclose conflicts of interest and to decline handling or reviewing manuscripts for which they may have a conflict of interest. The editors and reviewers of this article have no conflicts of interest.

Received for publication Sept 27, 2021; revisions received Sept 27, 2021; accepted for publication Sept 28, 2021.

Address for reprints: Abe DeAnda, Jr, MD, Division of Cardiovascular and Thoracic Surgery, UTMB-Galveston, 301 University Blvd, Galveston, TX 77551 (E-mail: abdeanda@utmb.edu).

J Thorac Cardiovasc Surg 2021; $\mathbf{\square}: 1-2$

0022-5223/ $\$ 36.00$

Copyright (c) 2021 by The American Association for Thoracic Surgery

https://doi.org/10.1016/j.jtcvs.2021.09.044
}

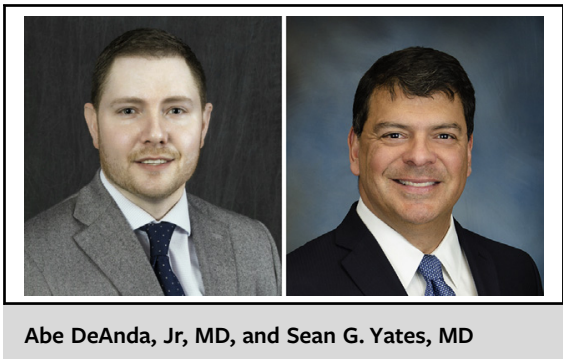

\section{CENTRAL MESSAGE \\ Thrombosis of the false lumen in aortic dissection may have long-term benefits. However, oral anticoagulation does not appear to increase the complication rate nor prevent thrombosis of the false lumen.}

risk for thromboembolic events (ie, patients receiving a mechanical aortic valve or with concomitant atrial fibrillation).

Vendramin and colleagues acknowledge some of the limitations of their study, including the low overall number of patients evaluated. Moreover, although the patient characteristics of the 2 groups were similar, the procedures they underwent were comparatively heterogeneous and may have influenced the reported morbidity and mortality rates. Notably, a much greater rate of isolated hemiarch procedure alone was conducted in patients not receiving OAC relative to patients receiving OAC $(87 \%$ vs $29 \%$, respectively).

The primary positive of this study was in the finding that the incidence of FL thrombosis was not significantly influenced by OAC, with an observed association between FL patency in patients receiving OAC and an increased frequency of partial thrombosis in patients not receiving OAC. Nevertheless, the incidence of complete thrombosis of the FL was comparable between both groups.

A possible explanation for these observations is suggested by a patient-specific computational model of type $\mathrm{B}$ dissection, demonstrating that both thrombus formation and growth were not only influenced by fluid shear rate, residence time, and platelet distribution but, most notably, the geometry of aortic dissection and its evolution over time. ${ }^{5}$ Consequently, this study suggests that thrombotic events associated with type B aortic dissection should be 
viewed as manifold and not simply a function of secondary hemostasis. When viewed through this prism, the findings reported by Vendramin and colleagues are not just those of another negative study but reinforce the idea that aortic pathophysiology is anything but simple.

\section{References}

1. Bernard Y, Zimmermann H, Chocron S, Litzler JF, Kastler B, Etievent JP, et al. False lumen patency as a predictor of later outcome in aortic dissection. Am J Cardiol. 2001;87:1378-82.
2. Trimarchi S, Tolenaar JL, Jonker FHW, Murray B, Tsai TT, Eagle KA, et al. Importance of false lumen thrombosis in type B aortic dissection prognosis. $J$ Thorac Cardiovasc Surg. 2013;145:S208-12.

3. Tsai TT, Evangelista A, Nienaber CA, Myrmel T, Meinhardt G, Cooper JV, et al. Partial thrombosis of the false lumen in patient with acute type B aortic dissection. N Engl J Med. 2007:357:349-59.

4. Vendramin I, Piani D, Lechiancole A, De Manna ND, Sponga S, Puppato M, et al. Do oral anticoagulants impact outcomes and false lumen patency after repair of acute type A aortic dissection? J Thorac Cardiovasc Surg. September 14, 2021 [Epub ahead of print].

5. Menichini C, Cheng Z, Gibbs RG, Xu XY. Predicting false lumen thrombosis in patient-specific models of aortic dissection. J R Soc Interface. 2016;124:20160759. 